\title{
COASTAL CHANGES AND MOVEMENTS IN THE WIDER VLORA (ALBANIA) AREA
}

\author{
U. Kanjir ${ }^{\text {a, * }, ~ N . ~ G r e g o r i c ̌ ~ B o n ~}$ \\ ${ }^{a}$ ZRC SAZU, Institute of Anthropological and Spatial studies, Department of remote sensing, Novi trg 2, 1000 Ljubljana, Slovenia - \\ ursa.kanjir@zrc-sazu.si \\ ${ }^{\mathrm{b}}$ ZRC SAZU, Institute of Anthropological and Spatial studies, Department of anthropology, Novi trg 2, 1000 Ljubljana, Slovenia - \\ natasa.gregoric@zrc-sazu.si
}

KEY WORDS: Change detection, change vector analysis, GEOBIA, urban growth, coastal erosion, migration, Albanian Riviera, ecology, anthropology, multidisciplinary research

\begin{abstract}
:
This paper explores the environmental change monitoring on the Albanian coastline (Vlora area) by analysing optical remote sensing data. Changes along this coastline are driven by coastal erosion and abusive urban construction of mostly tourist complexes and other man-made processes and pressures (e.g. sandpits, poor wastewater management, etc.). The change detection is based on yearly Landsat data of the period between 1984 and 2015. On the basis of mentioned images, each year's Normalized Difference Water Index (NDWI), Normalized Difference Build-up Index (NDBI) and Normalized Difference Vegetation Index (NDVI) are extracted. With the use of change vector analysis technique the combination of these indexes were then compared between each other. The quantitative extent of coastal changes was defined using geographic object-based image analysis (GEOBIA). By obtaining GEOBIA post-classification results we compared both change detection approaches of pairs of one period (2010-2015). The coastline and coastal change maps produced at $30 \mathrm{~m}$ resolution, applying both pixel- and object-based approaches, showed that CVA approach is a preferred technique when analysing Landsat data for coastal change detection. Apart from identifying spatial changes through time, the objective of this study is to show that these landscape changes correspond with the population movements and migrations. This study argues that movements of both people and landscape strongly impact each other and form an intertwining and corresponding relationship.
\end{abstract}

\section{INTRODUCTION}

Over the last decades, ecological environment has changed dramatically due to increasingly intensifying social and economic development. Accurate and timely information about land cover patterns and changes in urban areas is crucial for urban land management decision-making, ecosystem monitoring and urban planning. A large amount of environmental and social data at relatively high spatiotemporal resolutions has become available to monitor and manage natural resources, to assess environmental impact and to observe human patterns. These data are the foundation for better understanding of relationships and interactions between human and natural phenomena.

This study focuses on geomorphologic and demographic changes in wider Vlora area, as it is said that Albania is one of the countries with the highest levels of erosion and migration in Europe (Buchroithner, 2000; Grazhdani and Shumka, 2007; King, 2005; Vullnetari, 2012). This work is ongoing and in continuation of previous research on changes of natural and demographic movements (Kanjir and Gregorič Bon, 2016). It examines land changes detected on Landsat data from 1984 to 2015. Several scholars (Allen and Kupfer, 2000; Baker et al., 2007; Lorena et al., 2002; Xiaolu and Bo, 2011) have conducted studies of change detection using change vector analysis from Landsat data. Authors (Berberoglu and Akin, 2009) undertook a comparison of different change detection techniques in the Mediterranean environment and although different change detection algorithms have their own merits and advantages, change vector analysis resulted in the largest overall accuracy. We first applied change vector analysis on the multi-temporal remote sensing data, where we detected two major types of coastal changes seen in this area: coastal erosion and coastal urbanisation. Furthermore, change vector analysis approach was compared and evaluated with the post-classification change detection results obtained with the geographic object-based image analysis (GEOBIA). Post-classification comparison methods detect land cover change by comparing independently produced classifications of images from different dates (Rogan and Chen, 2004). GEOBIA is a frequently used technique in remote sensing and has demonstrated great potential for classification and change detection of high-spatial resolution multispectral imagery in heterogeneous urban environments (Boldt et al., 2012; Chen et al., 2012; Kanjir et al., 2011; Zhou et al., 2008).

Finally, this paper explores the demographical changes along the southern Albanian coastline using socioeconomic data. It questions if the correlation found between changes seen from optical satellite images and corresponding migration data of Albania from the last three decades could offer insights into the complex environmental and social changes.

\subsection{Changes on the Albanian coastline}

The Albanian coastline has faced abrupt changes in the course of the last decade. The country has over $400 \mathrm{~km}$ of coastline, approximately $150 \mathrm{~km}$ of which at its southern end is highly erosive (Gruda and Dollma, 2013) and of high ecological value. The entire stretch of southern coast, extending from Vlora to Ftelis Bay (Greece), has been a target of intense erosion, about $20-50 \mathrm{~cm}$ per year (Qiriazi and Sala, 2000). The causes of coastal erosion are related to several general and local factors, both human (e.g. removal of inert materials from the riverbeds and coastline, unplanned constructions, hydrological construction on the shores) and naturally driven (e.g. coastal terrigenous material, steep slopes, river deposits, irregular precipitation). Spatial distributions of annual coastal changes are valuable information for coastal monitoring and 
environmental assessment studies. In Albania there is poor periodic control of erosion and hardly any legal regulations are in place for coastal protection.

Apart from erosion being the main reason for land changes in this coastal area, rapid urbanisation has also had a great impact on the land changes, especially after the start of the new millennium when a greater amount of remittances were being sent by migrants, or around 2010 when many of the migrants started to return back home. These newly constructed sites along the coast tend to give priority to capital accumulation before any consideration of social values, and therefore do not follow any urban planning regime.

\subsection{Population movements in Albania}

Albania's population has been subject to migrations throughout the centuries and migrations still play a major role in the lives of many Albanians today. (Gregorič Bon, 2016) has shown how migration is embodied in people's' practices and is reified in the Albanian architecture. The exclusive period when migration flow in the area was abruptly stopped was in 1945 with the rise of the communist regime, when private ownership of cars was forbidden and in-country movements were limited. Nevertheless, due to the development of textile and food industry in Vlora in this period, many people living in rural areas moved to this coastal city. Major migrations out of the country started after 1990 with the collapse of the communist regime, when both authorized and unauthorized migration in Albania acquired epic proportions. Massive migration "exoduses" that have importantly influenced the Albanian politics, economy, society as well as landscape, took place at the beginning of 1990's (King, 2005; Vullnetari, 2012). After the year 2000, the number of migrants stabilised whereas the number of remittances and other material goods sent sporadically to home location increased. Remittances were often the main source of income for particular households and economies in Albania (Wong, 2006) and had influenced the rapid urbanisation of the area. Another important milestone marks the Albanian entrance into the Schengen Zone area in December 2010, which had a stabilizing effect on migration, but at the same time many migrants began to return due to fiscal and economic crisis in Greece and Italy. The years 2010 and 2011 report the largest number of return migration in relation to the total population living in Vlora (INSTAT, 2016), leading to an increase in the process of urbanisation in this area.

\section{DATA AND METHODOLOGY}

\subsection{Study site, data used and time slots}

This research focuses on the wider area of the city of Vlora, located in the southern part of Albania, facing the Adriatic Sea (see Figure 1). Vlora is the municipal seat of the eponymous County, one of the 12 Albanian counties, and it is the second largest port in Albania. Over the last decade, the city's coastal area is being affected by affronting urban construction of mostly touristic complexes (hotels, apartment houses, touristic villages, etc.). This study area therefore represents a complex scene, as the landscape varies in spatial and temporal terms, affected by different factors, both natural and anthropogenic, interacting with each other, and resulting in multiple consequences.

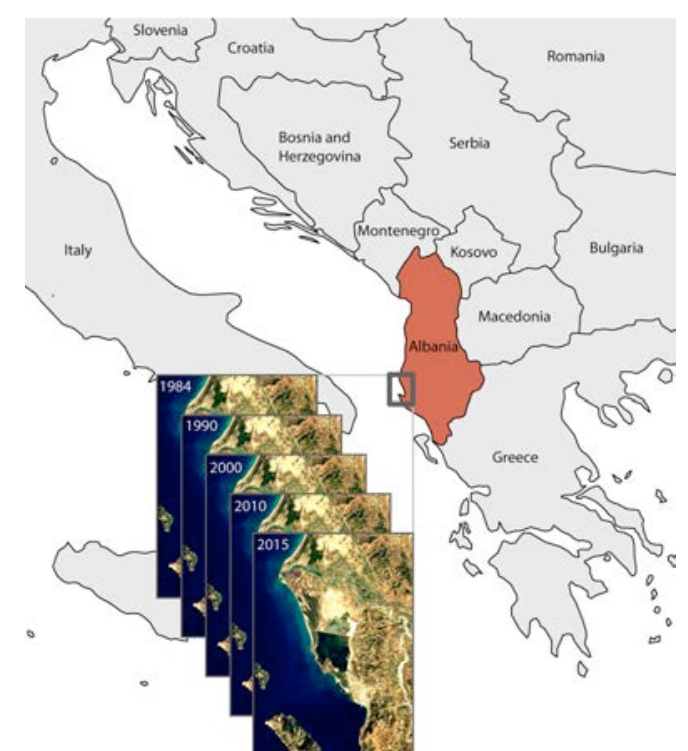

Figure 1. Location of the study area and Landsat data set.

The data set of this study is comprised of five Landsat data collected in 1984, 1990, 2000, 2010 and 2015. Time slots of Landsat data were selected deliberately, as they coincide with the periods of greater political changes in Albania:

- 1984 - 1990: communist regime (1945-90)/forbidden outcountry migrations, limited and controlled in-country migrations.

-1990 - 2000: fall of communism - transition period/massive migrations (mainly to Greece and Italy).

- 2000 - 2010: democracy/stabilized migration, remittances, growing number of returnees, in-country migrations.

- 2010 - 2015: Albania joins the Schengen Area/the number of migrations rises again in 2014.

All five Landsat images used were taken in the same season (late July-August-early September) in order to minimize change detection error introduced by seasonal differences. But for the Landsat 8 image from 2015, all other images are the product of Landsat 5 sensor. All multispectral images have $30 \mathrm{~m}$ of spatial resolution.

To describe population migration patterns for the particular time-periods we have used the INSTAT national statistical data.

\subsection{Image pre-processing}

Images acquired at different times usually have different amounts of haze and dust in the atmosphere. These differences can mask real changes or make similar land covers appear to have changed (Berberoglu and Akin, 2009). To overcome this problem, we applied atmospheric correction using ATCOR software. These corrections are important especially when comparing multi-temporal images (Jianya et al., 2008), e.g. when applying change vector analysis, as this technique is based on pixel-based radiometric comparison.

All images were also geometrically aligned between each other before the analysis. The importance of accurate spatial registration of multi-temporal imagery cannot be overstated, since mis-registration will give rise to false results. If high registration accuracy is not available (sub-pixel), image displacement will lead to inaccuracies in change detection scene.

Images were finally cropped to the desired geospatial extent corresponding to our study interest. 


\subsection{CVA Change detection}

There exist a number of change detection techniques, but none of them is universally optimal, as every method depends upon the application, data and the physical environment. Based on the results of research done by (Berberoglu and Akin, 2009) change vector analysis is the most appropriate model for handling the variability present in the Mediterranean land use/cover. We have used this method to obtain changes of erosion and urbanisation on the Albanian southern coast. The change vector analysis was implemented entirely with the use of open source software R.

Change vector analysis is a simple radiometric technique for land use/land cover change detection. It uses two spectral channels and calculates the magnitude of change and the direction of change between these two images (Malila, 1980). The direction or angle of the change vector is determined by the type of occurring change on the coastline (outline of coastal area) and/or at the coastal area. This procedure involves selecting a threshold to determine the extent of changed areas, and a conclusion on the extent of change is reached depending on whether the change magnitude exceeds a specific threshold.

In order to reduce the amount of redundant information for the detection of coastal erosion and urbanisation in our study area, we have used a combination of different band indexes instead of using satellite spectral bands directly. For the coastal erosion detection, we have used the combination of Normalized Difference Water Index (NDWI) and Normalized Difference Urban Index (UI) - or also called the build-up index (Zha et al., 2003). Furthermore, for the needs of urbanisation growth detection through time CVA we applied Normalized Difference Vegetation Index (NDVI) in combination with UI indexes. For a detailed description of these indexes please see (Kanjir and Gregorič Bon, 2016).

Results of changes in the coastal area of southern Albania detected with the CVA in the selected time periods were later compared with the statistical data of migrations that took place since the date of the first available satellite image from 1984 up until 2015. Before that, the CVA results of this pixel approach were compared with object change detection post-classification analysis, which is described below.

\subsection{GEOBIA classification}

Many Mediterranean land covers exhibit similar spectral characteristics making the separation in feature space by simple per-pixels classifiers difficult, leading to inaccurate classification (Berberoglu and Akin, 2009). We used objectbased approach to conduct the classification separately on the two Landsat images, from 2010 and 2015 respectively. With the GEOBIA approach, objects (segments) are first created and then used for further analysis. Object characteristics such as shape, spatial relations and reflectance statistics can be used for classification and change detection. In our procedure both times Landsat images were segmented using same segmentation parameters. Following the segmentation, we performed an example based feature extraction to classify each object into one of the classes. We were able to classify nine land cover classes on both images: sea, agriculture, urban environment, bare land, greenery, lagoon and shrubs.

Following the classification, we conducted a comparison of both land cover change detection methods for a period between 2010 and 2015 to obtain a change detection difference map.

\subsection{Accuracy assessment of classification}

Accuracy assessment of GEOBIA classification results was done using reference data created from visual interpretation. Stratified random samples were generated and it was determined whether they were correctly classified or not. A total number of 100 points were sampled, for each of the nine classes. Overall accuracies of both classification maps of 2010 and 2015 were $87.3 \%$ and $88.2 \%$ respectively. The final accuracy in GEOBIA strongly depends on the accuracy of the segmentation.

The change detection results derived from GEOBIA image pairs 2010-2015 were compared with CVA results of pairs of the same time period. OBIA change detection of selected period therefore serves as a verification methodology of the results obtained by CVA analysis.

\section{RESULTS}

\subsection{CVA}

3.1.1 Coastal erosion: The results of CVA show strong coastal erosion in the Vjosa river delta. It can be seen from the analysis of Landsat satellite images spanning the period 19842015 that delta erosion has progressively increased. The higher amount of yellow areas on the coast shows higher magnitude (or higher chance) of coastal changes between the selected dates (see Figure 2). Obvious delta shape changes of Vjosa River have probably resulted from the interaction between sediment discharge by the river, anthropogenic removal of coastal sediment, wave energy and tidal effects.
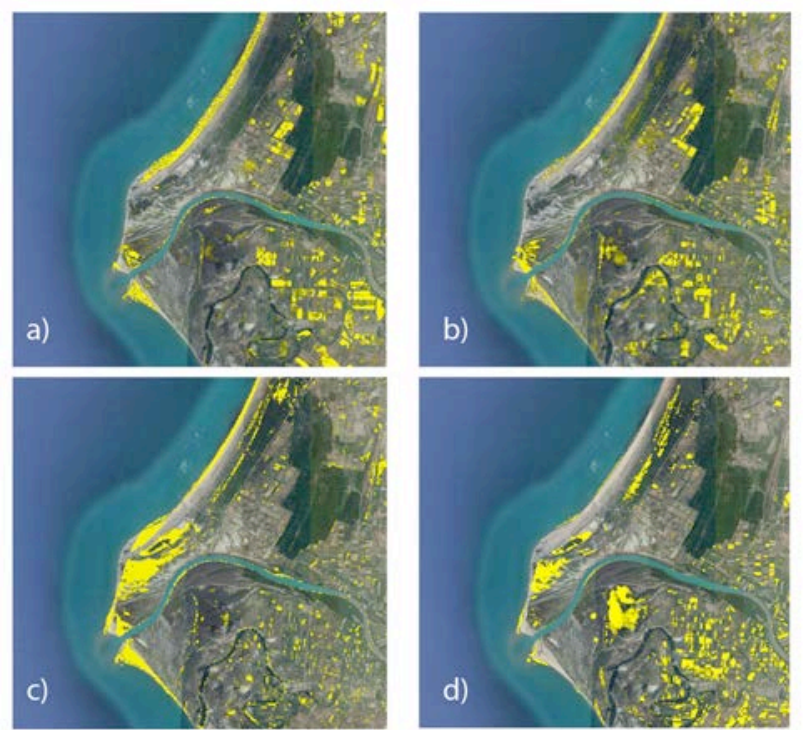

Figure 2. Change vector analysis results of the Vjosa delta area. The Figure presents changes in the periods of 1984-1990 (a), 1990-2000 (b), 2000-2010 (c) and 2010-2015 (d). Background layer on all sub-images is Google Earth image from 2015. 
3.1.2 Urban change: Urbanisation along the Albanian coast has been on a rapid increase since the late 1990s, which is when emigrants' revenue started to grow. This can be clearly seen from the results with the biggest change, taking place between 1990 and 2000 (Figure 3). The extent of urbanisation in and around the city of Vlora appears to be smaller than that brought about by coastal erosion in the delta of Vjosa River. This was expected, due to a lower spatial extent of constructions in the city compared to the greater deposits in Vjosa River.
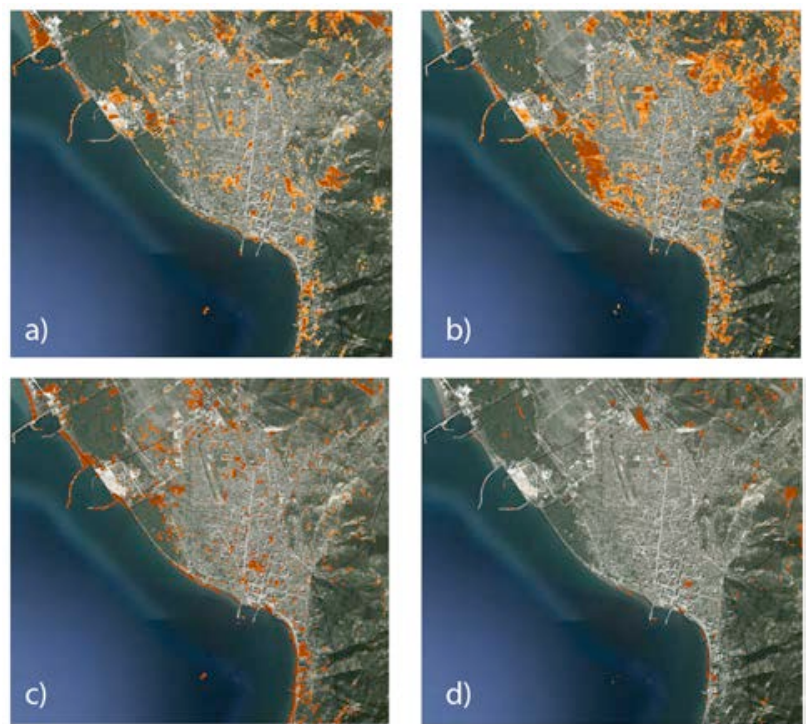

Figure 3. Changes of the urban areas through time in the city of Vlora. The Figure presents changes in the periods of 1984-1990 (a), 1990-2000 (b), 2000-2010 (c) and 2010-2015 (d). Background layer on all sub-images is Google Earth image from 2015.

\subsection{GEOBIA classification}

With the object-based approach we have obtained two classification images (see Figure 4), which were later analysed for change detection, also known as post-classification approach. Similar results as obtained with the CVA technique are detected also with the object-based approach. Major land cover changes can be seen for the most altering areas: at the delta of Vjosa River and around the city of Vlora.
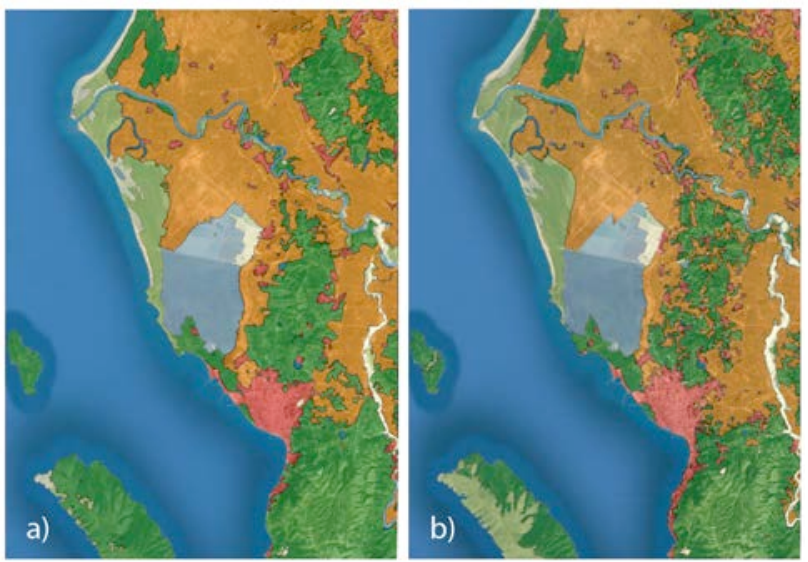

Figure 4. Object-based image analysis results for 2010 (a) and 2015 (b).

On the Figure 5 that shows change detection results from GEOBIA approach (red areas), vegetation changes in the inland can also be noted, but we have not given these changes any weight, as this is not within the scope of our interest. An important decrease in sediment on the coast is highlighted from Landsat data (green arrows), whereas sandy shoreline progradation in the mouth sector of the delta is the sediment brought by the river and by the tidal waves on the areas around the delta (black arrows).

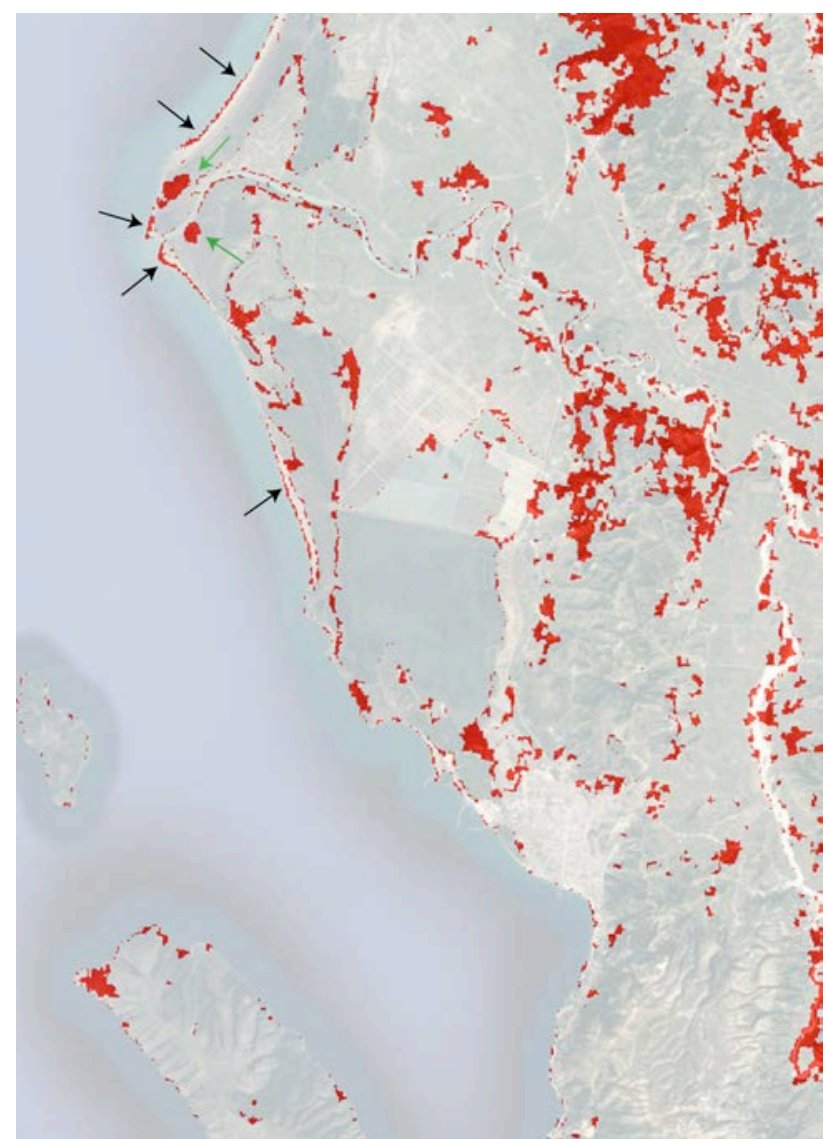

Figure 5. Figure shows change detection results (red areas) that have been detected between two classification maps obtained with the GEOBIA approach. Black arrows indicate progradation areas, whereas green arrows indicate loss of sediment in delta area.

\subsection{Comparison of both change analysis techniques}

Although land changes through time were detected with both change detection techniques, a profound visual examination of an experienced analyst shows that better change detection results are given with the CVA method. In order to test that, we have performed a comparison of change pixels from both techniques on the preselected area at the river delta. CVA approach has detected on the river delta on average $90 \mathrm{~m} \mathrm{(3}$ pixels) of coastal erosion, whereas GEOBIA approach detected $180 \mathrm{~m}$ (6 pixels) of change on average between the years 2010 and 2015 . The resolution of images is $30 \mathrm{~m}$; therefore one sample data (pixel) equals 900 square meters. According to visual estimation of erosion on the same evaluated areas there has been on average around 3 pixels of erosion during the 5 years, which indicates CVA's more exact result. GEOBIA approach performed poorer results due to the obvious exaggeration of object sizes while performing segmentation. CVA approach works on pixel level and is therefore more precise. We expect that the situation would be different when dealing with high-resolution data $(10 \mathrm{~m}$ or higher spatial resolution). 


\subsection{Correlation of land and socioeconomic changes}

While comparing the socio-economic data with the results from the remote sensing change detection analysis by periods, both changes correspond with each other (see Table 1).

\begin{tabular}{|l|l|l|}
\hline Date & Socioeconomic statistics & $\begin{array}{l}\text { Max width of } \\
\text { coastal } \\
\text { (CVA) }\end{array}$ \\
\hline Until 1990 & $\begin{array}{l}\text { Forbidden out country } \\
\text { migrations, limited and } \\
\text { controlled in-country } \\
\text { migrations }\end{array}$ & $<100 \mathrm{~m}$ \\
2000-2010 & $\begin{array}{l}\text { Massive migrations } \\
\text { Stabilized migration, } \\
\text { remittances, growing no. of } \\
\text { returnees, in-country } \\
\text { migration }\end{array}$ & $<400 \mathrm{~m}$ \\
2010-2015 & $\begin{array}{l}\text { Stable, the no. of migrations } \\
\text { rises again in 2014 }\end{array}$ & $<150 \mathrm{~m}$ \\
\hline
\end{tabular}

Table 1. Comparison of the data on migration and CVA results.

First period is marked with almost no migrations and only slight environmental changes. The most extensive migrations took place between 1990 and 2000, where at the same time river mouth mass changes of Vjosa substantially increased in comparison to the first period and the urbanisation growth is the most extensive in this era. The biggest environmental changes in Vjosa River are detected between 2000 and 2010 (up to 400 meters in width) when the migrations are stabilizing but remittances are at their highest, resulting in the most intense urbanisation growth in the Vlora area so far. In the last five years, when only half a decade has been taken into consideration, both migration and environmental changes are still under progress, but up to a much smaller extent than in the previous periods.

\section{CONCLUSION}

In this study we have shown that the environmental changes (coastal erosion and urbanization growth) have greatly influenced the wider Vlora area over the last thirty years. Our results of coastal changes driven by coastal erosion in the studied area confirm the findings of authors (Qiriazi and Sala, 2000), when they mention strong coastal erosion $(20-50$ $\mathrm{cm} /$ year) along the southern Albanian coastline. We argue that the main factor underpinning the erosion is connected with human induced changes in the area (e.g. material displacement). The vulnerability of the Vjosa delta involves a conjunction of various pressing issues attracting more and more scientific and political attention, underpinned by the tensions raised by the planned large hydropower dam projects up the Vjosa River, and the threats such projects pose for the sustainability of the river deltas in general. The future research will focus on the quantification and the extent of changes and their directions as detected from remote sensing data, and subject them to a statistical analysis.

At the same time we have performed a comparison between pixel- and object-based change detection in order to obtain the performance of CVA methodology on Landsat data, which we used as a main change detection methodology on this area. Coastal erosion and urban extension in the city of Vlora showed better performance while being detected with the CVA method comparing to GEOBIA changes, which is in accordance with Berberoglu and Akin (2009) statement. Future research anticipates similar change detection research on high-resolution data (e.g. Sentinel-2 data) to compare techniques and their performance on different remote sensing data.

The detected spatial changes correspond to the social, political, economic and demographic changes of Albania during our period of study. We can therefore state that the changes seen in the environment strongly indicate larger socio-economic, political and demographic changes taking place within the state.

\section{ACKNOWLEDGEMENTS}

This research has been funded by the Slovenian Research Agency (2014-2017).

\section{REFERENCES}

Allen, T.R., Kupfer, J.A., 2000. Application of Spherical Statistics to Change Vector Analysis of Landsat Data: Southern Appalachian Spruce-Fir Forests. Remote Sens. Environ., 74, pp. 482-493.

Baker, C., Lawrence, R.L., Montagne, C., Patten, D., 2007. Change detection of wetland ecosystems using Landsat imagery and change vector analysis. Wetlands, 27, pp. 610-619.

Berberoglu, S., Akin, A., 2009. Assessing different remote sensing techniques to detect land use/cover changes in the eastern Mediterranean. Int. J. Appl. Earth Obs. Geoinformation, 11, pp. 46-53.

Boldt, M., Thiele, A., Schulz, K., 2012. Object-based urban change detection analyzing high resolution optical satellite images. In: Michel, U., Civco, D.L., Ehlers, M., Schulz, K., Nikolakopoulos, K.G., Habib, S., Messinger, D., Maltese, A. (Eds.), Proc. SPIE 8538. Presented at the Earth Resources and Environmental Remote Sensing/GIS Applications III, p. $85380 \mathrm{E}$.

Buchroithner, M.F., 2000. Remote Sensing for Environmental Data in Albania: A Strategy for Integrated Management, Softcover reprint of the original 1st ed. 2000 edition. Springer, Dordrecht, Boston.

Chen, G., Hay, G.J., Carvalho, L.M.T., Wulder, M.A., 2012. Object-based change detection. Int. J. Remote Sens., 33, pp. 4434-4457.

Grazhdani, S., Shumka, S., 2007. New Water Culture of South East European Countries-AQUA 2005An approach to mapping soil erosion by water with application to Albania. Desalination, 213, pp. 263-272.

Gregorič Bon, N., 2016. Rooting Routes: (Non)Movements in Southern Albania. In: Gregorič Bon, N., Repič, J. (Eds.), Moving Places. Relations, Return and Belonging. Berghahn Books, Oxford, New York.

Gruda, G., Dollma, M., 2013. Albania. In: Pranzini, E., Williams, A. (Eds.), Coastal Erosion and Protection in Europe. Routledge, London, New York, pp. 345-354.

INSTAT, 2016. Instituti i Statistikave Republika e Shqiperise [WWW Document]. URL http://databaza.instat.gov.al (accessed 7.8.16). 
Jianya, G., Haigang, S., Guorui, M., Qiming, Z., 2008. A Review of Multi-Temporal Remote Sensing Data Change Detection Algorithms. In: The International Archives of the Photogrammetry, Remote Sensing and Spatial Information Sciences. Presented at the ISPRS Congress Beijing 2008, pp. 757-762.

Kanjir, U., Gregorič Bon, N., 2016. Spatial changes and population movements on the Albanian coastline. In: The International Archives of the Photogrammetry, Remote Sensing and Spatial Information Sciences. Presented at the ISPRS Congress Prague 2016.

Kanjir, U., Veljanovski, T., Oštir, K., 2011. Change detection of urban areas - the Ljubljana, Slovenia case study. In: 2011 Joint Urban Remote Sensing Event. Presented at the 2011 Joint Urban Remote Sensing Event, pp. 425-428.

King, R., 2005. Albania as a laboratory for the study of migration and development. J. South. Eur. Balk., 7, pp. 133155 .

Lorena, R.B., Shimabukuro, Y.E., Brown, I.F., Kux, H.J.J., 2002. A change vector analysis technique to monitor land use/land cover in SW Brazilian amazon: Acre state. Presented at the PECORA 15-Integrating Remote Sensing at the Global, Regional and Local Scale.

Malila, W.A., 1980. Change Vector Analysis: An Approach for Detecting Forest Changes with Landsat. In: Proceedings of the 6th Annual Symposium on Machine Processing of Remotely Sensed Data. Presented at the 6th Annual Symposium on Machine Processing of Remotely Sensed Data, Purdue University, West Lafayette, Indiana, pp. 326-335.

Qiriazi, P., Sala, S., 2000. Environmental Problems of Albania. In: Buchroithner, M.F. (Ed.), Remote Sensing for Environmental Data in Albania: A Strategy for Integrated Management, NATO Science Series. Springer Netherlands, pp. 13-30.

Rogan, J., Chen, D., 2004. Remote sensing technology for mapping and monitoring land-cover and land-use change. Prog. Plan., 61, pp. 301-325.

Vullnetari, J., 2012. Albania on the Move: Links Between Internal and International Migration. Amsterdam University Press.

Wong, M., 2006. The Gendered Politics of Remittances in Ghanaian Transnational Families. Econ. Geogr., 82, pp. 355381.

Xiaolu, S., Bo, C., 2011. Change Detection Using Change Vector Analysis from Landsat TM Images in Wuhan. Procedia Environ. Sci., 11, pp. 238-244.

Zha, Y., Gao, J., Ni, S., 2003. Use of normalized difference built-up index in automatically mapping urban areas from TM imagery. Int. J. Remote Sens., 24, pp. 583-594.

Zhou, W., Troy, A., Grove, M., 2008. Object-based Land Cover Classification and Change Analysis in the Baltimore Metropolitan Area Using Multitemporal High Resolution Remote Sensing Data. Sensors, 8, pp. 1613-1636. 